On copyright

\section{Copyright in the networked world: new rules for images}

\author{
Michael Seadle
}

\section{Introduction}

The district court found that Kelly had established a prima facie case of copyright infringement based on Arriba's unauthorized reproduction and display of Kelly's works, but that this reproduction and display constituted a non-infringing "fair use" under Section 107 of the Copyright Act. Kelly appeals that decision, and we affirm in part and reverse in part. The creation and use of the thumbnails in the search engine is a fair use, but the display of the larger image is a violation of Kelly's exclusive right to publicly display his works (Kelly v. Arriba, 2002).

Most photographs are "original" in one if not more of the three respects set out in the treatise and therefore are copyrightable. Plaintiff's problem here is that it seeks protection for the exception that proves the rule: photographs of existing two-dimensional articles (in this case works of art), each of which reproduces the article in the photographic medium as precisely as technology permits. Its transparencies stand in the same relation to the original works of art as a photocopy stands to a page of typescript, a doodle or a Michelangelo drawing. Plaintiff nevertheless argues that the photocopier analogy is inapt, because taking a photograph requires greater skill than making a photocopy and because these transparencies involved a change in medium. But the argument is as unpersuasive under British as under US law (Bridgeman v. Corel, 1999).

These two recent court cases have redefined how images may be used on the Internet without copyright infringement. The Bridgeman case is based explicitly on British as well as US law (the Bridgeman Art Library is British). The Kelly case rested entirely on the definition of fair use in Section 107 of the US copyright law (17 USC 107 (US Copyright Office, 2000)) and therefore, has more limited (or perhaps merely more complex) implications. While neither case suggests any tolerance for the unrestricted copying of images, they enable a vastly greater use of Web-based images than has been possible for those eager to follow the law.

\section{Precedent}

Photography came into existence after the origins of both the US and British copyright laws. In fact, the original US copyright law of 1790 covered only maps, charts and books. Etchings and engravings were added in 1802, 
and photographs and negatives not until 1865 (Bielefield and Cheeseman, 1997, p. 32). But once photographs received protection, essentially all photographs, regardless of the size or contents, had full protection. The justification for this rested on the amount of originality necessary to take any picture. "Any photograph reflects 'the personal influence of the author, and no two will be absolutely alike," wrote Judge Learned Hand (Nimmer et al., 1991, p. 53). This general rule that all photographs deserve protection persisted into the digital age without serious revision. In the Bridgeman case, Judge Lewis A. Kaplan still had to consider the precedent of the 1884 Burrow-Giles Lithographic Co. v. Sarony case, where the US Supreme Court "held that photographs are 'writings' within the meaning of the Copyright Clause and that the particular portrait at issue in that case was sufficiently original - by virtue of its pose, arrangement of accessories in the photograph lighting and the expression the photographer evoked - to be subject to copyright (Bridgeman v. Corel, 1999).

When Kaplan first ruled against the Bridgeman Art Library and overthrew over a century of legal tradition, he faced an uproar: "On November 23, 1998, plaintiff moved for reargument and reconsideration, arguing that the Court erred on the issue of originality" (Bridgeman v. Corel, 1999). Kaplan did reconsider, but his amended ruling was "more damaging to the status quo than the original" (Szczesny, 1999).

\section{Bridgeman v. Corel}

The heart of Kaplan's ruling had to do with attempting to reproduce a two-dimensional public domain art work "as precisely as technology permits." He decided that these photographs failed the required test of originality under both US and British law, since the plaintiffs admitted that "the goal of the transparencies is to be as true to the original work as possible" (Bridgeman v. Corel, 1999). He also cited the 1991 Feist v. Rural Telephone case as a precedent for discarding any claims of originality in the sweat-of-the-brow labor needed to make the photos.
The ruling throws into the public domain the large number of slides and photographs that art galleries and museums take of their most famous pre-twentieth century paintings. They sell these reproductions in the form of postcards, posters and slides in their gift shops and other venues in order to raise money. The fear that competitors would undercut the market with cheaper versions initially shook the mostly non-profit museum world. So far, however, disaster seems not to have struck.

On my last visit to the Philadelphia Museum of Art, for example, I bought two posters of public domain art (a Canaletto and a Monet), and I stood in a long line of others who were buying the same things. Because of the Bridgeman decision, I could legally digitize either poster, but I prefer viewing them full-size on my office wall instead of in miniature on my computer screen. Technology could change this. The prospect of projection monitors that cast large high-resolution digital images on to walls might compete seriously with printed posters. But until those monitors arrive, the lines at the art galleries may not grow noticeably shorter.

The full limits - and the further implications - of the decision remain unclear. For example, there are times when it could be a problem to know whether a photograph counts as a slavishly exact reproduction of a public domain work. Would an image of Rembrandt's Night Watch be in the public domain, if the colors had been altered to reflect how they might have looked when freshly painted, or to show how the painting looked in the nineteenth century before layers of grime were cleaned away? Those technical changes, presumably the result of human judgment, might well contribute sufficient originality for copyright protection.

It is not clear whether a photograph of a three-dimensional work, such as a statue, would count as being in the public domain, even if the original came from ancient Greece. One argument is that the photographer would have to exercise judgment about which side to pick, what perspective to use, even what light and shadow to allow. At the same time a QuickTime Virtual Reality (QTVR) three-dimensional representation of a statue might possibly count as public domain. In making a QTVR image, the photographer would need to take pictures of 
the statue at regular intervals around the object, every 30 degrees, for example. The statue would also need to be photographed from the top and bottom in an equally regular manner. Then software would stitch these images together to form a virtual representation that, like the original, could be viewed from all sides. Would any copyrightable originality remain? At this point, it is hard to tell. Judge Kaplan's decision focused narrowly on two-dimensional works.

The originality of pictures from automatic cameras might also be questioned. Security cameras are one example. Their output is not ordinarily of great interest to libraries, but recently the Pentagon released security camera photos of the airplane that crashed into the Pentagon on September 11, 2001. The historical importance of the event could make the photographs desirable for classroom and textbook use in coming years, and these photographs might not qualify as federal documents for a number of reasons (the cameras could have been part of a contract with a commercial security firm). Web-cams have a similar degree of automation in their imagemaking. Web-cam images of a construction site could be useful for architecture or engineering classes. But even an automated camera must be pointed in a certain direction. Future judges may need to decide whether that suffices for copyright protection.

\section{Kelly v. Arriba}

Judge Thomas G. Nelson wrote the decision in Kelly v. Arriba for the US Court of Appeals. For the first time, the court accepted thumbnail images as fair use under US law. The reasoning is important, because the decision does not authorize all uses of thumbnails. Fair use has four factors, and Nelson dealt with each in turn.

His reasoning on the first factor ("the purpose and character of the use, including whether such use is of a commercial nature or is for nonprofit educational purposes") was:

Kelly's images were among thousands of images in Arriba's search engine database. Because the use of Kelly's images was not highly exploitative, the commercial nature of the use only slightly weighs against a finding of fair use (Kelly v. Arriba, 2002).
The context of the images is worth noting. The thumbnails belonged to a larger collection not specifically aimed at the works of the plaintiff. Nelson continued:

The second part of the inquiry as to this factor involves the transformative nature of the use. We must determine whether Arriba's use of the images merely superseded the object of the originals or instead added a further purpose or different character. We find that Arriba's use of Kelly's images for its thumbnails was transformative (Kelly v. Arriba, 2002).

The use was transformative, because they were used to give access through the database.

Nelson's reasoning on the second factor ("the nature of the copyrighted work") was:

Photographs used for illustrative purposes, such as Kelly's, are generally creative in nature. The fact that a work is published or unpublished also is a critical element of its nature. Published works are more likely to qualify as fair use, because the first appearance of the artist's expression has already occurred. Kelly's images appeared on the Internet before Arriba used them in its search image. When considering both of these elements, we find that this factor only slightly weighs in favor of Kelly (Kelly v. Arriba, 2002).

If the photographs had not appeared already on the Web, this factor might have come out differently.

Nelson's reasoning on the third factor ("the amount and substantiality of the portion used in relation to the copyrighted work as a whole”) was:

This factor will weigh neither for nor against either party because, although Arriba did copy each of Kelly's images as a whole, it was reasonable to do so in light of Arriba's use of the images. It was necessary for Arriba to copy the entire image to allow users to recognize the image and decide whether to pursue more information about the image or the originating Web site. If Arriba only copied part of the image, it would be more difficult to identify it, thereby reducing the usefulness of the visual search engine (Kelly v. Arriba, 2002).

The ability to recognize the whole work is key to this argument, despite copying the whole work (even in miniature form).

Nelson's reasoning on the fourth factor ("the effect of the use on the potential market for or value of the copyrighted work") was:

Arriba's use of Kelly's images in its thumbnails does not harm the market for Kelly's images or the value of his images. By showing the thumbnails on its results page when users entered terms related to 
Copyright in the networked world: new rules for images

Michael Seadle

Kelly's images, the search engine would guide users to Kelly's Web site rather than away from it. Even if users were more interested in the image itself than the information on the Web page, they would still have to go to Kelly's site to see the fullsized image. The thumbnails would not be a substitute for the full-sized images, because, when the thumbnails are enlarged, they lose their clarity (Kelly v. Arriba, 2002).

The important issue here is that the thumbnails cannot substitute for the full-sized images. If they were so large that they did not lose clarity for some uses, this argument would not apply. It might also not apply in cases where a thumbnail image sufficed as a substitute (Baroni, 2002).

Thumbnail images are already ubiquitous on the Web. Some online catalogs are already able to use them to show the cover art for books. Cover art can be a factor in a reader's choice of the work and the art is an integral part of how the publisher intended the book to be presented. Thanks to Kelly v. Arriba, that kind of use of a thumbnail would appear to be non-infringing.

More aggressive uses, such as thumbnails of modern (copyright protected) art, might also be considered fair use for teaching or criticism or other transformative purposes, but this is not clear from Nelson's ruling. The necessary size of a thumbnail in relation to the whole also remains vague, though any thumbnail that could be expanded to substitute effectively for the original would clearly not qualify. This case is very new, and it will take time to understand fully its effect.

\section{Conclusion}

These two cases have fundamentally changed the rules for using images on the Web. Before them, essentially all photographs since 1923 had the presumption of copyright protection.
Now exact copies of public domain art, and perhaps other images that lack sufficient originality to qualify under the copyright laws, are in the public domain. And thumbnail copies of protected images can be regarded under at least some circumstances as being safely within the US fair use guidelines. Since anything on the Internet also allows international access, other members of the Berne Convention will have to come to terms with the legal existence of thumbnails too.

The Web has always been image-friendly. Now the number of legal images on the Web might be even greater.

\section{References}

Baroni, M. (2002), "Photos and fair use online: from Penthouse pets to Kelly's thumbnails", Gigalaw.com, Atlanta, GA, March, available at: www.gigalaw.com/ articles/2002-all/baroni-2002-03-all.html (accessed March 2002).

Bielefield, A.C. and Cheeseman, L.G. (1997), Technology and Copyright Law: A Guidebook for the Library, Research, and Teaching Professions, Neal-Schuman, New York, NY.

Bridgeman v. Corel (1999 amended), 1999 US Dist. LEXIS 1731, 2 March.

Kelly v. Arriba (2002, filed), 2002 U.S. App. LEXIS 1786, 6 February.

Nimmer, M., Marcus, P., Myers, D. and Nimmer, D. (1991), Cases and Materials on Copyright: And Other Aspects of Entertainment Litigation, including Unfair Competition, Defamation, Privacy, 4th ed., West Publishing, St Paul, MN.

Szczesny, B.G. (1999), excerpts from April 1999 American Association of Museums Annual Meeting Presentation, "What's Happening in Washington", April, available at: www.panix.com/ squigle/rarin/ corel2.html (accessed March 2002).

US Copyright Office (2000), United States Code, 17 USC 106A, Title 17, US Copyright Office, Washington, DC, Chapter 1, section 107, available at: www4.law. cornell.edu/uscode/17/107.html (accessed December 2001). 